\title{
Short Segment Fixation Versus Short Segment Fixation With Pedicle Screws at the Fracture Level for Thoracolumbar Burst Fracture
}

\author{
Anghel S1, Márton D² \\ ${ }^{1}$ PhD Student, University of Medicine and Pharmacy, Tîrgu Mureș, Romania \\ ${ }^{2}$ Clinic of Orthopedics, County Emergency Clinical Hospital, Tîrgu Mureș, Romania
}

\begin{abstract}
Objective: The most prevailing surgical procedure in the treatment of thoracolumbar burst fractures, Short Segment Fixation (SSF), is often followed by loss of correction or hardware failure which may be significant enough to require another surgical intervention. In order to take advantage of its benefits but to avoid or diminish the risk and impact of associated drawbacks, some other alternatives have been lately developed among which we refer to short segment fixation with intermediate screws (SSF+IS). This article provides a comparative picture over the effectiveness of the two above-mentioned surgical treatments, focusing on their potential to prevent the loss of correction.

Methods: After a systematic literature review over research papers published between 2000 and 2012, 14 articles which met the criteria were included in the meta-analysis. The relevant data extracted and compared for each subgroup of patients treated either with SSF or SSF+IS, were the weighted averages for the pre-operative, post-operative and last follow up kyphosis angles. We also considered common associated complications, operation time, and blood loss values for each surgical subgroups.

Results: The values for the loss of correction at the last follow-up were: $5.5^{\circ}$ for SS and $7.4^{\circ}$ for SSF+IS, which didn't prove to be statistically different. With reference to other parameters, such as operation time, blood loss and correction attainment, the values did not present statistically significant differences, either. Regarding complications, we noticed that both SSF and SSF+IS display a similar incidence for hardware failure, screw breakages, superficial infections, deep venous thrombosis.

Conclusions: This paper concludes that, adding one or two screws at the fractured vertebra level (SSF+IS) does not bring forth a significant improvement compared to the traditional approach (SSF). Apparently, the blood loss depends mostly on the approach type (open or percutaneous) and less on the surgery type.
\end{abstract}

Keywords: burst fracture, thoracolumbar spine, kyphosis, loss of correction

Received: 11 June 2013 / Accepted: 9 April 2014

\section{Introduction}

Despite considerable clinical experience and scientific research along the last 3-4 decades, the treatment of thoracolumbar fracture is still controversial [1].

The most frequent surgery treatment for thoracolumbar burst fracture with one fracture level is posterior short segment fixation (SSF) [2]. The SSF procedure, which involves one level above and one beneath the fractured vertebral body, presents multiple advantages, such as: facile reduction of the fracture; correction of the kyphosys angle; primary fracture stabilization allowing the patient's early mobilization; good spinal mobility, given the small number of fixed vertebrae.

The main disadvantages associated with SSF are related to long-term low stability in the anterior damaged spine [3]. Bio-mechanical analyses reveal a relatively low SSF device rigidity, up to $40-70 \%$ of the integral spinal rigidity $[2,4]$. Therefore, loss of correction, screw breakages, or even failure of treatment are relatively frequent secondary complications of the SSF $[5,6]$.

In order to lower the frequency and severity of complications, but to take advantage of specific SSF benefits,

Correspondence to: Anghel Stelian

E-mail: steliananghel@yahoo.com various techniques have been designed, among which this article would refer to short segment fixation with one or two screws at the fracture level $(\mathrm{SSF}+\mathrm{IS})$, pursuing three main objectives: to improve reduction, to lend support to the anterior spine and to increase the rigidity of the device.

Inserting one or two intermediate transpedicular screws at the fracture level [6] improves reduction due to the three abutments [7] and is theoretically supposed to increase the device resistance, as it stabilizes the intermediate vertebra.

Drawing on available research work, this article contributes to the literature with an extended meta-analysis of 14 articles comprising over 200 subjects, which provides a relevant and substantiated picture over the comparative effectiveness of the two surgical approaches mentioned above. Our research results may be of assistance in the decision making process over the treatment of patients with thoracolumbar burst fractures.

\section{Methods}

Using "spinal fracture", "burst fracture", "short-segment fixation" and "kyphoplasty" as search parameters, we performed a systematic literature review over research papers published between 2000 and 2012, available in the Sciencedirect, Ovid and PubMed databases. 
The selected articles cumulatively met the following inclusion criteria:

- adult patient lot with at least 10 subjects with traumatic, non-osteoporotic thoracolumbar fracture;

- one fracture level, T5-L5;

- fully described surgical treatment, allowing for its classification;

- at least 9 months follow-up;

- the values for pre-operative, post-operative, followup and loss of correction of kyphosys angles, at least, are specified.

The selected papers were classified according to the surgical method involved, resulting two categories:

1. short posterior segment fixation with transpedicular screws at the vertebral levels above and beneath fractured level (SSF);

2. short posterior transpedicular segment fixation with "intermediate screws" (SSF+IS).

After thorough reading, we extracted the most relevant parameters necessary to pertinently compare the two surgical treatment methods (see Table I). From papers presenting comparative analysis between two or more treatment procedures, or biomecanical testing, were retained solely the data in accordance with our study requirements.

The recorded data were statistically processed and analysed using the Comprehensive Meta Analysis Software, version 2.2.064. Weighted averages have been computed in a random-effect model, given a high level of betweenstudy heterogeneity (as $\mathrm{I}^{2}>90 \%$ ).

\section{Results}

Fourteen articles published between 2000 and 2012 have been found to comply with our study specifications. It is worth noting that there were several studies providing data for more than one procedure. Therefore, we refer to 12 articles for SSF [7-18], and 5 for SSF+IS [7,8,19-21].

The total number of patients comprised in our study is 462. Fractures were positioned between T6 and L5, classified as mainly A class (A1, A2, A3) AO fractures for SSF and SSF+IS, but not only. We recorded some cases of $\mathrm{B}$ and $\mathrm{C}$ category, as well.

The weighted means of the preoperative kyphosis angles were $18.9 \pm 0.82$ for SSF and $17 \pm 0.83$ for SSF+IS. Between

Table I. Relevant parameters for comparative analysis

\begin{tabular}{ll}
\hline No. & Parameter \\
\hline 1. & Lot size (number of patients) \\
2. & Subjects age \\
3. & Fracture type \\
4. & Fracture level \\
5. & Surgery duration \\
6. & Mean kyphosis angle \\
& $\begin{array}{l}\text { prooperative } \\
\text { postoperative }\end{array}$ \\
& last follow-up \\
7. & Loss of reduction \\
8. & Complications \\
\hline
\end{tabular}

SSF+IS and SSF values, there was no significant statistical difference. The weighted average for post-operative kyphosis angles were $5.37 \pm 1.1$ for SSF and $4.53 \pm 0.76$ for SSF+IS, with no significant statistical differences. We would like to mention that for each of the mean measures computed, there was no statistically significant difference between SSF and SSF+IS. Reduction achieved with SSF was of $13.07 \pm 1$ and of $12.91 \pm 1.31$ for SSF+IS. The last follow-up loss of correction was, on average, $5.52 \pm 0.8$ for SSF and 7.48 \pm 1.59 for SSF+IS.

Regarding complications, some papers presented details, other briefly mentioned them, while some authors made no reference on these matters. Therefore, we haven't been able to conduct statistical analysis on these data. Yet, we have noted that the most frequent complications were similar in frequency and order for the SSF and SSF+IS categories: the most prevalent in both classes were implant failure, followed by vicious screw positioning, superficial infections, deep venous thrombosis. The SSF group presented also one case of screw loosening.

We also calculated averages for operative time and blood loss for somewhat smaller groups of studies $[4,7,8,10,14,21]$, as not all of the papers provided this information. It turned out that a non-significant statistical difference occurs between SSF and SSF+IS regarding operative time (140 min vs. $134 \mathrm{~min}$ ) and that the values for blood loss are not significantly different either (see Table II).

\section{Discussion}

Short segment fixation (SSF) remains the most common surgical treatment for one thoracal or lumber vertebral body fracture. The relatively small number of fixed segments ensures higher patient mobility [17]. It provides support for all three spinal segments [18] and decompresses the vertebral canal if PLL is unaffected $[1,19]$. The procedure is relatively simple and presents low morbidity, being, thus, preferred and recommended in case of politrauma. The major disadvantage lays in the high incidence of long-term loss of reduction or implant failure $[18,20]$.

This high rate has been often explained with the inability of instrumentation to provide the necessary support to the injured anterior spine. Biomechanical tests have revealed that SSF device rigidity is significantly (52\%) lower against flexion-compression forces and axial forces compared to undamaged spine [4].

Intermediate screws insertion ( $\mathrm{SSF}+\mathrm{IS})$ increase rigidity to flexion forces. Moreover, three support ends instead of two improve the fracture correction [22]. Biomechani-

Table II. Means for blood loss and surgery time

\begin{tabular}{lccc}
\hline & SSF & SSF+IS & Obs. \\
\hline Number of patients & 126 & 84 & \\
Surgery duration (minutes) & $140.8 \pm 9.55$ & $134.9 \pm 13.9$ & $\mathrm{~ns}^{*}$ \\
Bleeding (ml) & $414.5 \pm 60.7$ & $283 \pm 109.4$ & $\mathrm{~ns}$ \\
\hline
\end{tabular}

${ }^{*}$ ns - non-significant statistical difference 
cal testing shows that SSF+IS improves rigidity to flexion forces up to $69 \%$ of the healthy spine resistance [4] and up to $84 \%$ of SSF device rigidity [23]. This extra rigidity might prevent loss of correction. Osman observed, in his prospective study, that the level of correction and vertebral body height preservation obtained in SSF+IS is equivalent to long posterior fixation [7].

Yet, Daniel Gelb et al. remarked there is no statistically significant difference between SSF and SSF+IS, regarding loss of correction [19]. Korovesis also compares SSF+IS with one stage $360^{\circ}$ stabilization and fusion and states that SSF+IS does not confer the needed stability, as it couldn't prevent the average $5^{\circ}$ loss of correction.

Our study suggests that SSF+Is offers a slightly improved reduction compared to SSF (postoperative mean kyphosis angles were $13.6 \pm 0.99$ for SSF, as compared to $12.9 \pm 1.3$ for SSF+IS), yet the loss of correction is lower for SSF $(5.5 \pm 0.79)$ than $S S F+I S(7.4 \pm 1.5)$. From a statistical point of view, the differences are, nevertheless, not significant.

Based on spinal $x$-ray, various authors noticed that the loss of correction is caused by the intervertebral disc whose space narrows down $[17,24]$ because of the intervertebral disc which breaks into the fractured vertebral body and remains there [25]. It has been noticed that, during trauma, the vertebral disc penetrates the vertebral endplate, usually the upper one and intrudes into the vertebral body. When the reduction is performed with ligamentotaxie, the annulus fibrosum abates the endplate edges - to which it is tightly connected - and reduces the vertebral body extremities, reconditioning its height. The nucleus pulposus, which is not that firmly attached to the center of the vertebral endplate, will reduce the endplate to a lesser extent, staying inside the vertebral body [26]. The cavity thus created would eventually be filled either with spongious bone tissue, or with fibrous tissue, which is referred to, in the literature, as Eggshell deformity. The Eggshell deformity seems to be not enough resistant in order to bear all compression forces. Bao-shanXu [24] revealed that $88 \%$ of CT investigated cases presented this type of cavity (Eggshell deformity), invariably connected to the upper vertebral disc. None of the above methods seem successful.

Concerning the loss of blood during surgery, SSF+IS presented the least blood loss volume (about $283 \mathrm{ml}$ on average) due to the high percentage of minim-invasive interventions. SSF and SSF+IS performed percutaneously also reported limited bleeding $(75 \mathrm{ml}$ and $83 \mathrm{ml}$, respectively) $[16,27]$.

\section{Conclusions}

Considering our research, we may conclude that adding one or two screws at the fractured vertebra level does not bring forth significant improvement, compared to SSF.

It seems that the blood loss during surgery depends to a higher extent on the approach type (open or percutaneous) and less on the surgery type (SSF, SSF+IS). This hypothesis needs further research for clarification.

\section{Acknowledgement}

This paper is partly supported by the Sectorial operational Programme Human Resources Development (SOP HRD), financed from the European Social Fund and by the Romanian Government under the contract number POSDRU 80641.

\section{References}

1. Verlaan JJ, Diekerhof CH, Buskens E, et al. Surgical Treatment of Traumatic Fractures of the Thoracic and Lumbar Spine. Spine. 2004;29(7):803-814.

2. George M, Wahba M, Bhatia N, et al. Biomechanical Evaluation of ShortSegment Posterior Instrumentation With and Without Crosslinks in a Human Cadaveric Unstable Thoracolumbar Burst Fracture Model. Spine. 2010;35(3):278-285.

3. Verlaan JJ, van Helden WH, Oner FC, Verbout AJ, Dhert WJA. Balloon Vertebroplasty with Calcium Phosphate Cement Augmentation for Direct Restoration of Traumatic Thoracolumbar Vertebral Fractures. Spine. 2002;27(5):543-548.

4. Mahar A, Kim C, Wedemeyer M, et al. Short-Segment Fixation of Lumbar Burst Fractures Using Pedicle Fixation at the Level of the Fracture. Spine. 2007;32(14):1503-1507.

5. Gurwitz GS, McNamara MJ, et al. Biomechanical analysis of three surgical approaches for lumbar burst fractures using short-segment instrumentation. Spine. 1993;18:977-982.

6. McLain RF, Benson DR. Early failure of short-segment pedicle instrumentation for thoracolumbar fractures. A preliminary report. J Bone Joint Surg Am. 1993;75:162-116.

7. Guven O, Kocaoglu B, Bezer M, Aydin N, Nalbantoglu U. The Use of Screw at the Fracture Level in the Treatment of Thoracolumbar Burst Fractures. J Spinal Disord Tech. 2009;22:417-421.

8. Wang $H$, Zhou Y, Zhang Z, Wang J, and Chu T. Percutaneous pedicle screw fixation through the pedicle of fractured vertebra in the treatment of type A thoracolumbar fractures using Sextant system: an analysis of 38 cases. Chinese Journal of Traumatology. 2010;13(3):137-145.

9. Altay M, Aktekin CM, Ozturk AM, Tabak AY. Treatment of unstable thoracolumbar junction burst fractures with short- or long-segment posterior fixation in magerl type a fractures. Eur Spine J. 2007;16:11451155.

10. Wei FX, Liang CX, Li HM. Transpedicular Fixation in Management of Thoracolumbar Burst Fractures Monosegmental Fixation Versus ShortSegment Instrumentation Spine. 2010;35(15):E714-E720.

11. Shi J, Liu J, Jiang W, Moral MZ, Ebraheim NA, Yang $H$. The influence of correction loss in thoracolumbar fractures treated by posterior instrumentation: A minimum 7-year follow-up. Journal of Clinical Neuroscience. 2011;11:500-503.

12. Celebi L, Muratli HH, Yagmurlu MF, Bicimoglu A. The effectiveness of short-segment posterior instrumentation of thoracolumbar burst fractures. Acta Orthop Traumatol Turc. 2007;41(3):183-189.

13. Ayvaz M, Alanay A, Acaroglu RE. Minimal invasive short posterior instrumentation plus balloon kyphoplasty with calcium phosphate for burst and severe compression lumbar fractures. Spine (Phila Pa 1976). 2009;34(22):2473; author reply 2473-2475.

14. Li J. Retrospective analysis of treatment of thoracolumbar burst fracture using mono-segment pedicle instrumentation compared with shortsegment pedicle instrumentation. Eur Spine J. 2012;21:2034-2042.

15. Lakshmanan P, Jones A, Mehta J, Ahuja S, Davies PR, Howes JP. Recurrence of kyphosis and its functional implications after surgical stabilization of dorsolumbar unstable burst fractures. The Spine Journal. 2009;9:1003-1009.

16. Ni WF, Huang YX, Chi YL, et al. Percutaneous Pedicle Screw Fixation for Neurologic Intact Thoracolumbar Burst Fractures. J Spinal Disord Tech. 2010;23:530-537.

17. Canto FRT, Defino HLA. Low thoracic and lumbar burst fractures: radiographic and functional outcomes. Eur Spine J. 2007;16(11):19341943.

18. Wang $X Y, X u H Z$, Chi YL. Biomechanical effect of the extent of vertebral body fracture on the thoracolumbar spine with pedicle screw fixation: An in vitro study. Journal of Clinical Neuroscience. 2008;15:286-290.

19. Gelb D, Ludwig S, Karp JE, et al. Successful Treatment of Thoracolumbar Fractures With Short-segment Pedicle Instrumentation. J Spinal Disord Tech. 2010;23(5).293-301.

20. Shen WJ, Liu TJ, Shen YS. Nonoperative Treatment Versus Posterior Fixation for Thoracolumbar Junction Burst Fractures Without Neurologic Deficit. Spine. 2001;26(9):1038-1045. 
21. Wang ST, Ma HL, Liu CL et al., Is Fusion Necessary for Surgically Treated Burst Fractures of the Thoracolumbar and Lumbar Spine? Spine. 2006;31(23):2646-2652

22. Anekstein Y, Brosh T, Mirovsky Y. Intermediate Screws in Short Segment Pedicular Fixation for Thoracic and Lumbar Fractures A Biomechanical Study J Spinal Disord Tech. 2007;20:72-77.

23. Dick JC, Jones MP, Zdeblick TA, Kunz DN, Horton WC.: A biomechanical comparison evaluating the use of intermediate screws and cross-linkage in lumbar pedicle fixation. J Spinal Disord. 1994;7(5):402-407.

24. Xu BS, Tang TS, Yang HL. Long-term results of thoracolumbar and lumbar burst fractures after short-segment pedicle instrumentation, with special reference to implant failure and correction loss. Orthopaedic Surgery. 2009;1(2):85-93.

25. Leferink WJM , Veldhuis EFM, ten Vergert EM, ten Duis HJ. Thoracolumbar spinal fractures: radiological results of transpedicular fixation combined with transpedicular cancellous bone graft and posterior fusion in 183 patients. Eur Spine J. 2001;10:517-523.

26. Oner FCM, Verlaan JJ, Verbout AJ, Dhert WJA. Cement Augmentation Techniques in Traumatic Thoracolumbar Spine Fractures. Spine. 2006;31(11 Supl):S89-S95.

27. Ni WF, Huang YX, Chi YL et al. Percutaneous pedicle screw fixation for neurologic intact thoracolumbar burst fractures. J Spinal Disord Tech. 2010;23(8):530-537. 